\title{
Self-trapped hole and impurity-related broad luminescence in $\beta-\mathrm{Ga}_{2} \mathrm{O}_{3}$
}

Cite as: J. Appl. Phys. 127, 075701 (2020); https://doi.org/10.1063/1.5140742

Submitted: 30 November 2019 . Accepted: 02 February 2020 . Published Online: 18 February 2020

Y. K. Frodason (D), K. M. Johansen (D), L. Vines, and J. B. Varley (D)

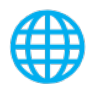

Lock-in Amplifiers Find out more today

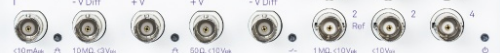

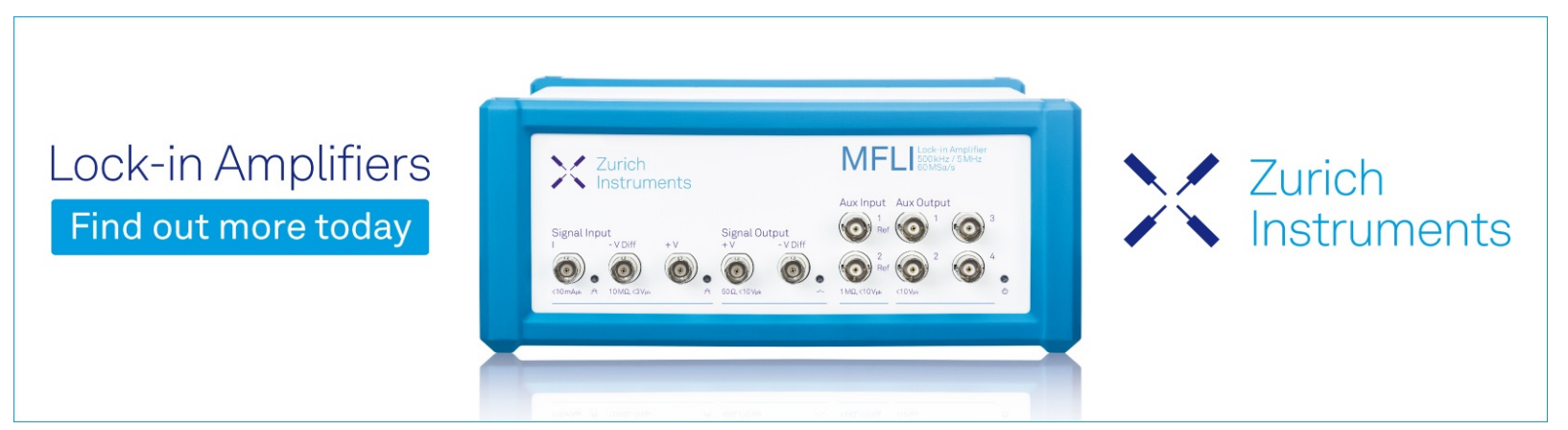




\title{
Self-trapped hole and impurity-related broad luminescence in $\beta-\mathrm{Ga}_{2} \mathrm{O}_{3}$
}

Cite as: J. Appl. Phys. 127, 075701 (2020); doi: 10.1063/1.5140742

Submitted: 30 November 2019 . Accepted: 2 February 2020 .

Published Online: 18 February 2020

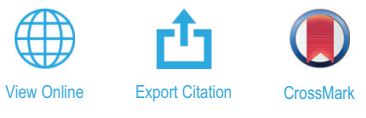

Y. K. Frodason, ${ }^{1, a)}$ (D) K. M. Johansen, ${ }^{1}$ (D) L. Vines, ${ }^{1}$ and J. B. Varley ${ }^{2}$ (D)

\begin{abstract}
AFFILIATIONS
${ }^{1}$ Department of Physics/Centre for Materials Science and Nanotechnology, University of Oslo, N-0318 Oslo, Norway

${ }^{2}$ Lawrence Livermore National Laboratory, Livermore, California 94550, USA
\end{abstract}

Note: This paper is part of the Special Topic on Defects in Semiconductors 2020.

a) Author to whom correspondence should be addressed: ymirkf@fys.uio.no

\begin{abstract}
This work explores the luminescence properties of self-trapped holes and impurity-related acceptors using one-dimensional configuration coordinate diagrams derived from hybrid functional calculations. The photoluminescence spectrum of as-grown $\beta$-Ga $\mathrm{O}_{3}$ typically consists of a broad band in the wavelength region from ultraviolet to green and is often dominated by an impurity independent ultraviolet band that is commonly attributed to self-trapped holes. Here, we use the self-trapped hole as a benchmark to evaluate the accuracy of the theoretical defect luminescence spectra and estimate the optical properties of $\mathrm{Mg}_{\mathrm{Ga}}, \mathrm{Be}_{\mathrm{Ga}}, \mathrm{Ca}_{\mathrm{Ga}}, \mathrm{Cd}_{\mathrm{Ga}}, \mathrm{Zn}_{\mathrm{Ga}}, \mathrm{Li}_{\mathrm{Ga}}$, and $\mathrm{N}_{\mathrm{O}}$ acceptor impurities, as well as their complexes with hydrogen donors. We also explore $V_{\mathrm{Ga}}$ acceptors complexed with hydrogen and $\mathrm{Si}_{\mathrm{Ga}}$ donor impurities. The results show that these defects can give rise to broad luminescence bands peaking in the infrared to visible part of the spectrum, making them potential candidates for the defect origin of broad luminescence bands in $\beta-\mathrm{Ga}_{2} \mathrm{O}_{3}$.
\end{abstract}

Published under license by AIP Publishing. https://doi.org/10.1063/1.5140742

\section{INTRODUCTION}

The monoclinic phase of gallium oxide $\left(\beta-\mathrm{Ga}_{2} \mathrm{O}_{3}\right)$ has drawn considerable attention in recent years. Its unique optical and electrical properties, including a wide bandgap $(\sim 4.9 \mathrm{eV})$ and a high breakdown field $(\sim 8 \mathrm{MV} / \mathrm{cm})$, make it a promising material for applications in, e.g., high-power electronics and UV sensors. ${ }^{1}$ This technological development will require a good understanding of the defect structure of $\beta-\mathrm{Ga}_{2} \mathrm{O}_{3}$, including native defects, impurities, and complexes thereof. To this avail, spectroscopic identification of the ruling defects, ${ }^{2,3}$ e.g., by using photoluminescence (PL) spectroscopy, is essential.

The luminescence spectrum of $\beta-\mathrm{Ga}_{2} \mathrm{O}_{3}$ does not exhibit near band-edge emission (NBE), but often consists of several broad luminescence bands in the spectral range between 2.3 and $4.5 \mathrm{eV}$, which are typically divided into three main spectral components: the ultraviolet (UVL), blue (BL), and green (GL) luminescence bands. These luminescence bands have been extensively characterized in terms of their dependence on temperature, ambient conditions, and dopant concentrations. ${ }^{4-12}$ The lack of NBE has been attributed to self-trapped holes (STHs), ${ }^{13,14}$ which are believed to form self-trapped excitons that recombine and give rise to an impurity independent, and often dominant, broad UVL band in the emission spectrum. ${ }^{4,8-12}$ This UVL band is only observed for excitation energies above the bandgap and exhibits a large Stokes shift, which is indicative of a strong electron-phonon coupling caused by highly localized charge carriers involved in the recombination. ${ }^{4}$ Recently, the UVL band has been resolved into high and low energy components, where the low band is polarized parallel to the $c$ axis of the crystal, and the high band is polarization independent. $^{8,12}$ Donor-acceptor pair recombination involving deep acceptors like $V_{\mathrm{Ga}}, V_{\mathrm{Ga}} V_{\mathrm{O}}$ complexes, $\mathrm{Mg}_{\mathrm{Ga}}, \mathrm{Be} \mathrm{Ga}_{\mathrm{Ga}}, \mathrm{Li}_{\mathrm{Ga}}, \mathrm{Zn}_{\mathrm{Ga}}$, and $\mathrm{N}_{\mathrm{O}}$ have been suggested as candidates responsible for the luminescence bands peaking in the visible part of the emission spectrum. $^{5-8,10,11,15-17}$ However, the specific defect origins of the majority of PL bands in $\beta$ - $\mathrm{Ga}_{2} \mathrm{O}_{3}$ remain a subject of debate.

Defect luminescence lines can be estimated theoretically by using configuration coordinate (CC) diagrams derived from firstprinciples calculations. ${ }^{18-20}$ This can be highly useful to interpret experimental PL data. ${ }^{20}$ In the present work, we employ hybrid functional calculations and the effective one-dimensional (1D) CC model to estimate the optical transition energies and luminescence lines of a selection of acceptor impurities in $\beta-\mathrm{Ga}_{2} \mathrm{O}_{3}$, namely, 
$\mathrm{Mg}_{\mathrm{Ga}}, \mathrm{Be}_{\mathrm{Ga}}, \mathrm{Ca}_{\mathrm{Ga}}, \mathrm{Cd}_{\mathrm{Ga}}, \mathrm{Zn}_{\mathrm{Ga}}, \mathrm{Li}_{\mathrm{Ga}}$, and $\mathrm{N}_{\mathrm{O}}$. These impurities are typical contaminants in as-grown $\beta-\mathrm{Ga}_{2} \mathrm{O}_{3}$ crystals, and/or potentially useful as compensating acceptor dopants to obtain highresistive or semi-insulating material. ${ }^{21-25}$ We have also investigated their interaction with hydrogen. Indeed, $\mathrm{H}_{\mathrm{i}}$ acts exclusively as a shallow donor in $\beta-\mathrm{Ga}_{2} \mathrm{O}_{3}$ and is likely to be trapped by acceptor impurities. $^{26-28}$ Finally, we have explored the optical properties of $V_{\mathrm{Ga}}$ acceptors complexed with shallow donor impurities hydrogen and $\mathrm{Si}_{\mathrm{Ga}}$. The $\mathrm{STH}$ is used as a benchmark to assess the accuracy of our results, as most of the acceptors studied here exhibit a similar polaronic defect state. Our predictions provide useful input for future optical studies on $\beta-\mathrm{Ga}_{2} \mathrm{O}_{3}$.

\section{METHODOLOGY}

All first-principles calculations were based on the generalized Kohn-Sham theory with the projector augmented wave method, ${ }^{29,30}$ as implemented in the VASP code. ${ }^{31}$ The Ga $3 d, 4 s$, $4 p ; \mathrm{O} 2 s, 2 p ; \mathrm{Mg} 2 p, 3 s ; \mathrm{Be} 2 s ; \mathrm{Cd} 5 s, 4 d$; Ca $3 s, 3 p, 4 s ; \mathrm{Zn} 3 d, 4 s$; Li $1 s, 2 s$; and $\mathrm{N} 2 s, 2 p$ electrons were treated as explicit valence states. To obtain an accurate description of the electronic and structural properties of $\beta-\mathrm{Ga}_{2} \mathrm{O}_{3}$, we used the Heyd-ScuseriaErnzerhof (HSE) ${ }^{32}$ range-separated hybrid functional. The screening parameter $\mu$ was fixed at the standard value, ${ }^{32}$ and the fraction of screened Hartree-Fock exchange was set to $\alpha=0.33$, resulting in a direct bandgap of $4.9 \mathrm{eV}$. The indirect bandgap is only $40 \mathrm{meV}$ lower in energy. ${ }^{33}$ This parameterization does not necessarily guarantee an accurate description of defect states, as is evident from the increasing use of Koopmans compliant functionals aiming to ensure that the total energy is a piece-wise linear function of the fractional electron number. ${ }^{34-38}$ For instance, Gake et al. ${ }^{39}$ recently reported that the polaronic defect states of the STH and $\mathrm{Mg}_{\mathrm{Ga}}$ acceptor in $\beta-\mathrm{Ga}_{2} \mathrm{O}_{3}$ exhibit slightly convex behavior, i.e., the single-particle level of the defect state shifts up in energy upon electron occupation. In order to assess how sensitive our results are to the HSE parameterization and elaborate on possible non-Koopmans behavior, some calculations were also performed using the PBE0 functional, as shown in the Appendix, which also yields a direct bandgap of $4.9 \mathrm{eV}$. We find that the peak positions (PPs) of the calculated luminescence lines change by less than $0.1 \mathrm{eV}$ when PBE0 is used. Both functionals result in slightly convex behavior for the defects studied here, similar to what was reported by Gake et al. ${ }^{39}$

For defect calculations, we employed 160-atom supercells, a plane-wave energy cutoff of $500 \mathrm{eV}$, and a single special $k$-point at $(0.25,0.25,0.25)$. Thermodynamic charge-state transition levels of defects are given by the Fermi level position for which the total energy of the defect-containing supercell in charge-states $q$ and $q \pm 1$ and relaxed configurations $Q(q)$ and $Q(q \pm 1)$ is equal,

$$
\varepsilon(q / q \pm 1)=E[q \pm 1 ; Q(q \pm 1)]-E(q ; Q(q)) \mp \varepsilon_{\mathrm{VBM}} .
$$

Here, $\varepsilon(q / q \pm 1)$ is given relative to the energy level of the valence band maximum (VBM) $\varepsilon_{\mathrm{VBM}}$. For vertical charge-state transitions, the configuration is fixed to that of the initial charge-state $Q(q)$, and the level is given by

$$
\mu(q / q \pm 1)=E[q \pm 1 ; Q(q)]-E(q ; Q(q)) \mp \varepsilon_{\mathrm{VBM}} .
$$

For charged defects, the total energies in Eq. (1) were corrected by using the anisotropic ${ }^{40}$ Freysoldt, Neugebauer, and Van de Walle (FNV) scheme, ${ }^{41}$ with the low-frequency dielectric tensor. ${ }^{42}$ For Eq. (2), we used the correction scheme newly developed by Gake et al. ${ }^{43}$ We performed tests to verify the performance of the latter correction scheme for the defects studied in the present work; these tests are shown in the Appendix.

Optical transition energies and luminescence lines were estimated by using the 1D CC model with parameters obtained from the hybrid functional calculations, as described in Refs. 18-20. These parameters include the change in configuration coordinate $\Delta Q$, the zero-phonon line (ZPL) energy $E_{\mathrm{ZPL}}$ [given by the thermodynamic charge-state transition level defined in Eq. (1)], and the effective phonon frequencies $\Omega_{\mathrm{g} / \mathrm{e}}$ in the ground (g) and excited (e) state. In the classical Franck-Condon (FC) approximation, optical transitions are vertical [given by Eq. (2)], which means the emission and absorption energies can be defined as $E_{\mathrm{em}}=E_{\mathrm{ZPL}}-d_{\mathrm{g}}^{\mathrm{FC}}$ and $E_{\mathrm{abs}}=E_{\mathrm{ZPL}}+d_{\mathrm{e}}^{\mathrm{FC}}$, respectively. Here, $d_{\mathrm{g} / \mathrm{e}}^{\mathrm{FC}}$ denotes FC relaxation energies. The 1D CC model is a good approximation for defects exhibiting strong electron-phonon coupling, ${ }^{18,20}$ which is the case for all defects studied in the present work.

\section{RESULTS AND DISCUSSION}

The $\beta-\mathrm{Ga}_{2} \mathrm{O}_{3}$ crystal structure contains two inequivalent $\mathrm{Ga}$ sites and three inequivalent $\mathrm{O}$ sites, as indicated in Fig. 1(a). Gal and $\mathrm{Ga} 2$ are tetrahedrally and octahedrally coordinated, respectively. Two $\mathrm{O}$ sites are threefold-coordinated: $\mathrm{O} 1 \quad(2 \times \mathrm{Ga} 2$, $1 \times \mathrm{Ga} 1)$ and $\mathrm{O} 2(2 \times \mathrm{Ga} 1,1 \times \mathrm{Ga} 2)$, while the $\mathrm{O} 3$ site is fourfold coordinated $(3 \times \mathrm{Ga} 2,1 \times \mathrm{Ga} 1)$.

\section{A. Self-trapped holes}

Before addressing the impurities, we consider optical transitions involving the STHs. Photogenerated holes can self-trap onto two different $\mathrm{O}$ sites, namely, $\mathrm{O} 1$ and $\mathrm{O} 2$. As shown in Fig. 1, the hole state is localized at a single $\mathrm{O}$ atom for $\mathrm{STH}_{\mathrm{O} 1}$ and shared between two $\mathrm{O}$ atoms for $\mathrm{STH}_{\mathrm{O} 2}$. The calculated hole self-trapping energies (defined in Ref. 13) of 0.48 and $0.49 \mathrm{eV}$ for $\mathrm{STH}_{\mathrm{O} 1}$ and $\mathrm{STH}_{\mathrm{O} 2}$ are nearly equivalent, which can be understood from their similar, nearly planar bonding environments to three Ga neighbors. These self-trapping energies correspond to ZPL energies of 4.38 and $4.37 \mathrm{eV}$ for the capture of an electron at the conduction band minimum $(\mathrm{CBM})$ by $\mathrm{STH}_{\mathrm{O} 1}$ and $\mathrm{STH}_{\mathrm{O} 2}$. As indicated in the $\mathrm{CC}$ diagrams in Fig. 1(b), these transitions result in emission energies of 3.04 and $2.95 \mathrm{eV}$. When the full luminescence lines are calculated by including vibronic coupling, ${ }^{18}$ the corresponding peak positions (PPs) occur at 3.11 and $3.05 \mathrm{eV}$ in the spectrum, as shown in Fig. 1(c). The CC model parameters, PP, and full-width at half maximum (FWHM) for all luminescence lines calculated in the present work are provided in Table I. The calculated PL bands of $\mathrm{STH}_{\mathrm{O} 1}$ and $\mathrm{STH}_{\mathrm{O} 2}$ are broad, with $\mathrm{FWHM}$ values of 0.54 and $0.62 \mathrm{eV}$, respectively. This broadness is caused by the sizable polaronic lattice distortion that accompanies the hole localization. 
a)

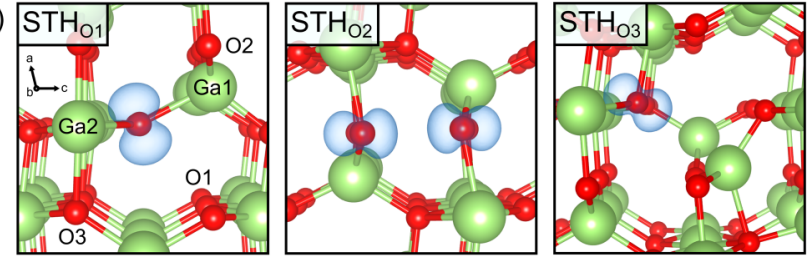

b)
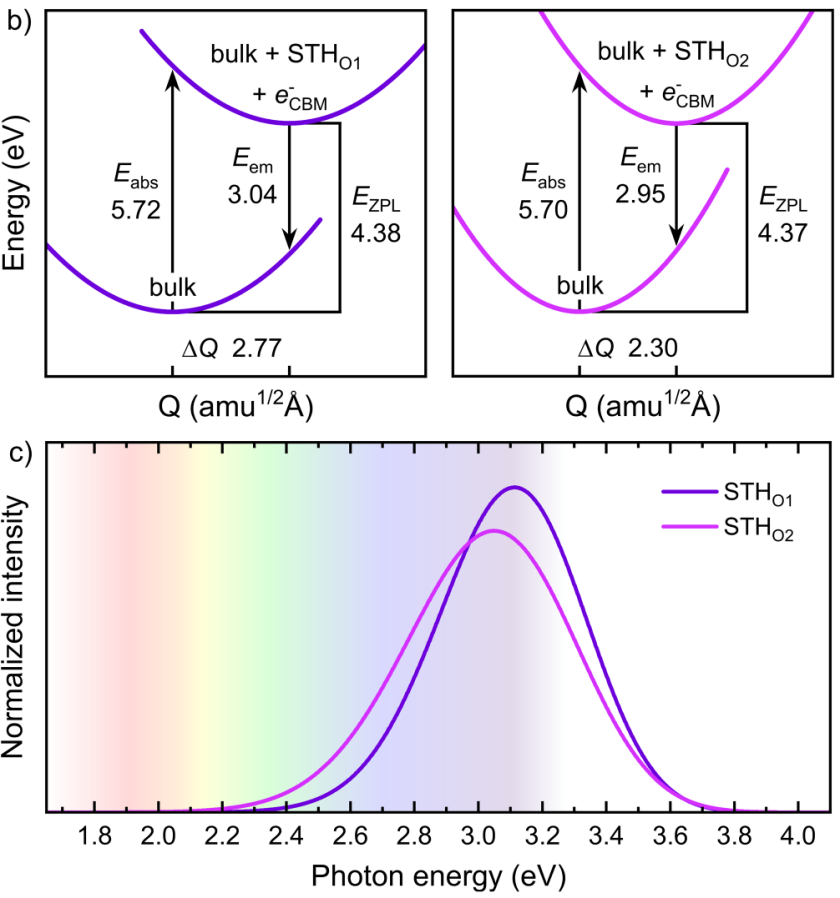

FIG. 1. (a) Relaxed structure of $\mathrm{STH}_{01}, \mathrm{STH}_{02}$, and $\mathrm{STH}_{03}$. The hole (blue isosurface) can be localized at one $\left(\mathrm{STH}_{01}\right.$ and $\left.\mathrm{STH}_{\mathrm{O}_{3}}\right)$ or shared between two $\left(\mathrm{STH}_{\mathrm{O}_{2}}\right) \mathrm{O}$ atoms. $\mathrm{STH}_{\mathrm{O} 3}$ is only metastable and involves breaking the O3-Ga1 bond. (b) CC diagrams for optical transitions involving recombination between $\mathrm{STH}_{\mathrm{O} 1}$ and $\mathrm{STH}_{\mathrm{O} 2}$ with free electrons at the CBM, and (c) the corresponding calculated luminescence lines.

As shown in Fig. 1(a), holes can also localize on the $\mathrm{O} 3$ sites. This has not been reported previously. The $\mathrm{O} 3$ site has four Ga neighbors and, therefore, occupies a very different bonding environment compared to the $\mathrm{O} 1$ and $\mathrm{O} 2$ sites. Hole trapping on the O3 site causes significant lattice distortions and breaks the single O3-Gal bond. The Gal atom is displaced sufficiently to form a new bond with a nearby $\mathrm{O} 2$ atom, thus preserving the tetrahedral coordination. However, $\mathrm{STH}_{\mathrm{O} 3}$ is only metastable with a negative self-trapping energy of $-0.33 \mathrm{eV}$ and is thus not expected to form relative to the other two STHs.

Experimentally, the STHs have been associated with a broad UVL band peaking in the spectral range $3.1-3.6 \mathrm{eV}^{4,7-10,12}$ The luminescence lines calculated for the STHs peak at the lower end of this range, which may indicate that they are somewhat underestimated. This would reflect the remaining inaccuracy of the hybrid functional calculations (e.g., non-Koopmans behavior), and the uncertainty of the experimental bandgap of $\beta-\mathrm{Ga}_{2} \mathrm{O}_{3} .{ }^{44}$ The calculated difference between the $\mathrm{PP}$ of $\mathrm{STH}_{\mathrm{O} 1}$ and $\mathrm{STH}_{\mathrm{O} 2}$ is consistent with the difference between the two components of the UV band reported in Ref. 12.

\section{B. Polaronic acceptor impurities}

Next, we consider Ga substitutional single acceptor impurities exhibiting polaronic defect states, similar to the STHs, namely, $\mathrm{Mg}_{\mathrm{Ga} 2}, \mathrm{Ca}_{\mathrm{Ga} 2}, \mathrm{Cd}_{\mathrm{Ga} 2}, \mathrm{Zn}_{\mathrm{Ga}}$, and $\mathrm{Be}_{\mathrm{Ga}}$. These impurities, along with $\mathrm{N}_{\mathrm{O}}$, were predicted to have the lowest formation energy in a survey of acceptor impurities performed by Lyons et al. ${ }^{22}$ For each impurity, we have considered the Ga site resulting in the lowest formation energy, as reported elsewhere. ${ }^{22,23}$ For polaronic acceptors, it is important to explore the different possible hole configurations. ${ }^{45,46}$ As shown in Fig. 2(a), the charge-neutral $\mathrm{Mg}_{\mathrm{Ga} 2}$ acceptor corresponds to a small hole polaron localized on a single nearest-neighbor O1 site, in line with experimental magnetic resonance data ${ }^{47}$ and previous theoretical studies, ${ }^{22,28}$ whereas hole localization on the $\mathrm{O} 2$ site is $0.12 \mathrm{eV}$ higher in energy. For $\mathrm{Ca}_{\mathrm{Ga} 2}, \mathrm{Cd}_{\mathrm{Ga} 2}, \mathrm{Zn}_{\mathrm{Ga}}$, and $\mathrm{Be}_{\mathrm{Ga}}$, the hole will also most favorably localize on an adjacent $\mathrm{O} 1$ site. In general, we find that hole polarons prefer to localize on the nearestneighbor $\mathrm{O}$ site with the lowest coordination number.

Similar to the STHs, optical transitions involving the capture of an electron at the $\mathrm{CBM}$ by charge-neutral $\mathrm{Mg}_{\mathrm{Ga} 2}, \mathrm{Ca}_{\mathrm{Ga} 2}, \mathrm{Cd}_{\mathrm{Ga} 2}$, $\mathrm{Zn}_{\mathrm{Ga}}$, and $\mathrm{Be}_{\mathrm{Gal}}$ are estimated. Note that these transitions involve the same type of polaronic defect state as $\mathrm{STH}_{\mathrm{O} 1}$, and thus, assuming that the PPs of the STHs are slightly underestimated, the error could be systematic. The $\mathrm{Mg}_{\mathrm{Ga} 2}, \mathrm{Ca}_{\mathrm{Ga} 2}, \mathrm{Cd}_{\mathrm{Ga} 2}$, and $\mathrm{Zn}_{\mathrm{Ga} 1}$ acceptors give rise to broad luminescence bands with predicted peak positions in the visible range between 2.15 and $2.62 \mathrm{eV}$, as shown in Fig. 2(b). In contrast, the calculated luminescence band for $\mathrm{Be}_{\mathrm{Ga}}$ peaks significantly lowers at $1.71 \mathrm{eV}$. This is mainly because the thermodynamic $(0 /-)$ transition level of $\mathrm{Be}_{\mathrm{Ga}}$ is deeper, ${ }^{22}$ and also because the ground-state relaxation energy is higher. The latter difference is likely related to the relatively small size of the Be ion, which undergoes a comparatively large displacement away from the localized hole, as shown in Fig. 2(a). This is similar to the polaronic $\mathrm{Li}_{\mathrm{Zn}}$ acceptor in $\mathrm{ZnO}{ }^{48}$ In principle, optical transitions involving metastable hole configurations can also occur. As an example, we have included results for charge-neutral $\mathrm{Mg}_{\mathrm{Ga} 2}$ with the hole localized on the $\mathrm{O} 2$ rather than the $\mathrm{O} 1$ site, which we label as pO2 (see Table I). Finally, we have studied the double acceptor $\mathrm{Li}_{\mathrm{Ga} 2}$. The optical transition between the $\mathrm{CBM}$ and the $(-/ 2-)$ level of $\mathrm{Li}_{\mathrm{Ga} 2}$ results in a luminescence band with a calculated peak position of $1.56 \mathrm{eV}$. This is significantly lower than those of the single polaronic acceptors, except $\mathrm{Be}_{\mathrm{Ga}}$.

Acceptor impurities present stable trapping sites for $\mathrm{H}_{\mathrm{i}}$ donors in $\beta-\mathrm{Ga}_{2} \mathrm{O}_{3}$. For instance, the $\mathrm{Mg}_{\mathrm{Ga} 2} \mathrm{H}$ complex has been assigned to an infrared (IR) absorption line at $3492 \mathrm{~cm}^{-1} .{ }^{28}$ We find that such complexes are not fully passivated, but rather exhibit a thermodynamic $(+/ 0)$ transition level close to the VBM. Note that a donor level is also predicted for the isolated acceptors. ${ }^{49}$ This incomplete passivation means that the complexes can be optically active. We have investigated $\mathrm{Mg}_{\mathrm{Ga} 2} \mathrm{H}, \mathrm{Ca}_{\mathrm{Ga} 2} \mathrm{H}$, $\mathrm{Be}_{\mathrm{Ga} 1} \mathrm{H}, \mathrm{Zn}_{\mathrm{Ga}} \mathrm{H}$, and $\mathrm{Cd}_{\mathrm{Ga} 2} \mathrm{H}$ (as shown in Table I). For these complexes, $\mathrm{H}$ most favorably binds to one of the $\mathrm{O} 1$ ions 
TABLE I. Peak position (PP) and full-width at half maximum (FWHM) for the calculated luminescence lines, and CC model parameters obtained from the HSE calculations, including ZPL energy $\left(E_{\mathrm{ZPL}}\right)$, classical emission $\left(E_{\mathrm{em}}\right)$ and absorption $\left(E_{\mathrm{abs}}\right)$ energies, total mass-weighted distortion $(\Delta Q)$, and effective normal mode frequencies in the ground/excited state $\left(\hbar \Omega_{\mathrm{g} / \mathrm{e}}\right)$.

\begin{tabular}{|c|c|c|c|c|c|c|c|}
\hline Optical transition & $\mathrm{PP}(\mathrm{eV})$ & FWHM $(\mathrm{eV})$ & $E_{\mathrm{ZPL}}(\mathrm{eV})$ & $E_{\mathrm{em}}(\mathrm{eV})$ & $E_{\mathrm{abs}}(\mathrm{eV})$ & $\Delta Q\left(\mathrm{amu}^{1 / 2} / \AA\right)$ & $\hbar \Omega_{\mathrm{g} / \mathrm{e}}(\mathrm{meV})$ \\
\hline $\mathrm{STH}_{\mathrm{O} 1}^{+}+e_{\mathrm{CBM}}^{-}$ & 3.11 & 0.54 & 4.38 & 3.04 & 5.58 & 2.77 & $38 / 36$ \\
\hline $\mathrm{STH}_{\mathrm{O} 2}^{+}+e_{\mathrm{CBM}}^{-}$ & 3.04 & 0.62 & 4.37 & 2.95 & 5.56 & 2.30 & $47 / 43$ \\
\hline $\mathrm{Mg}_{\mathrm{Ga} 2}^{0, \mathrm{pO} 1}+e_{\mathrm{CBM}}^{-}$ & 2.32 & 0.59 & 3.69 & 2.21 & 4.86 & 2.67 & $42 / 37$ \\
\hline $\mathrm{Mg}_{\mathrm{Ga} 2}^{0, \mathrm{pO} 2}+e_{\mathrm{CBM}}^{-}$ & 2.53 & 0.63 & 3.81 & 2.41 & 4.92 & 2.14 & $50 / 44$ \\
\hline $\mathrm{Ca}_{\mathrm{Ga} 2}^{0}+e_{\mathrm{CBM}}^{-}$ & 2.40 & 0.57 & 3.75 & 2.30 & 4.89 & 2.83 & $39 / 34$ \\
\hline $\mathrm{Cd}_{\mathrm{Ga} 2}^{0}+e_{\mathrm{CBM}}^{-}$ & 2.62 & 0.55 & 3.67 & 2.52 & 4.47 & 2.26 & $43 / 36$ \\
\hline $\mathrm{Zn}_{\mathrm{Ga1}}^{0}+e_{\mathrm{CBM}}^{-}$ & 2.15 & 0.57 & 3.48 & 2.04 & 4.64 & 2.70 & $41 / 36$ \\
\hline $\mathrm{Be}_{\mathrm{Ga} 1}^{0}+e_{\mathrm{CBM}}^{-}$ & 1.71 & 0.64 & 3.25 & 1.54 & 4.63 & 2.61 & $46 / 41$ \\
\hline $\mathrm{Li}_{\mathrm{Ga} 2}^{-}+e_{\mathrm{CBM}}^{-}$ & 1.56 & 0.62 & 2.96 & 1.37 & 4.00 & 2.65 & $44 / 35$ \\
\hline$\left(\mathrm{Mg}_{\mathrm{Ga} 2} \mathrm{H}\right)^{+}+e_{\mathrm{CBM}}^{-}$ & 2.71 & 0.55 & 4.00 & 2.63 & 5.20 & 2.67 & $40 / 37$ \\
\hline$\left(\mathrm{Ca}_{\mathrm{Ga} 2} \mathrm{H}\right)^{+}+e_{\mathrm{CBM}}^{-}$ & 2.76 & 0.53 & 4.03 & 2.68 & 5.17 & 2.90 & $37 / 34$ \\
\hline$\left(\mathrm{Cd}_{\mathrm{Ga} 2} \mathrm{H}\right)^{+}+e_{\mathrm{CBM}}^{-}$ & 2.90 & 0.55 & 3.99 & 2.81 & 4.71 & 2.58 & $39 / 30$ \\
\hline$\left(\mathrm{Zn}_{\mathrm{Ga} 1} \mathrm{H}\right)^{+}+e_{\mathrm{CBM}}^{-}$ & 2.75 & 0.57 & 3.98 & 2.66 & 5.11 & 2.42 & $43 / 40$ \\
\hline$\left(\mathrm{Be}_{\mathrm{Gal}} \mathrm{H}\right)^{+}+e_{\mathrm{CBM}}^{-}$ & 2.57 & 0.60 & 3.95 & 2.47 & 5.28 & 2.51 & $44 / 42$ \\
\hline$\left(V_{\mathrm{Ga}}^{\mathrm{ib}}\right)^{0}+e_{\mathrm{CBM}}^{-}$ & 1.93 & 0.62 & 3.33 & 1.78 & 4.46 & 2.59 & $44 / 38$ \\
\hline$\left(V_{\mathrm{Ga} 2} \mathrm{Si}_{\mathrm{Ga} 1}\right)^{-}+e_{\mathrm{CBM}}^{-}$ & 1.17 & 0.59 & 2.47 & 0.93 & 3.44 & 2.52 & $45 / 36$ \\
\hline$\left(V_{\mathrm{Ga}}^{\mathrm{ib}} 2 \mathrm{H}\right)^{0}+e_{\mathrm{CBM}}^{-}$ & 2.12 & 0.64 & 3.57 & 1.97 & 4.71 & 2.59 & $44 / 38$ \\
\hline$\left(V_{\mathrm{Ga}}^{\mathrm{ib}} 3 \mathrm{H}\right)^{+}+e_{\mathrm{CBM}}^{-}$ & 2.54 & 0.60 & 3.95 & 2.43 & 5.12 & 2.74 & $41 / 36$ \\
\hline$\left(V_{\mathrm{Ga}}^{\mathrm{ic}} 2 \mathrm{H}\right)^{0}+e_{\mathrm{CBM}}^{-}$ & 1.95 & 0.60 & 3.47 & 1.82 & 4.91 & 2.84 & $41 / 38$ \\
\hline$\left(V_{\mathrm{Ga}}^{\mathrm{ic}} \mathrm{Si}_{\mathrm{i}} 2 \mathrm{H}\right)^{+}+e_{\mathrm{CBM}}^{-}$ & 2.55 & 0.63 & 3.90 & 2.43 & 5.12 & 2.31 & $48 / 44$ \\
\hline $\mathrm{N}_{\mathrm{O} 1}^{+}+e_{\mathrm{CBM}}^{-}$ & 2.28 & 0.58 & 3.69 & 2.17 & 4.99 & 2.80 & $40 / 37$ \\
\hline $\mathrm{N}_{\mathrm{O} 2}^{+}+e_{\mathrm{CBM}}^{-}$ & 2.92 & 0.59 & 4.25 & 2.83 & 5.22 & 2.77 & $39 / 32$ \\
\hline $\mathrm{N}_{\mathrm{O} 3}^{0}+e_{\mathrm{CBM}}^{-}$ & 1.44 & 0.59 & 2.85 & 1.27 & 4.04 & 2.77 & $41 / 36$ \\
\hline $\mathrm{N}_{\mathrm{O} 3}^{+}+e_{\mathrm{CBM}}^{-}$ & 1.87 & 0.55 & 3.37 & 1.76 & 4.74 & 3.40 & $34 / 31$ \\
\hline$\left(\mathrm{N}_{\mathrm{Ol}} \mathrm{H}\right)^{+}+e_{\mathrm{CBM}}^{-}$ & 2.25 & 0.60 & 3.91 & 2.13 & 5.36 & 3.32 & $37 / 33$ \\
\hline$\left(\mathrm{N}_{\mathrm{O} 2} \mathrm{H}\right)^{+}+e_{\mathrm{CBM}}^{-}$ & 2.65 & 0.64 & 4.20 & 2.53 & 5.30 & 3.00 & $39 / 32$ \\
\hline$\left(\mathrm{N}_{\mathrm{O} 3} \mathrm{H}\right)^{+}+e_{\mathrm{CBM}}^{-}$ & 2.10 & 0.49 & 3.50 & 2.02 & 4.92 & 3.62 & $31 / 30$ \\
\hline
\end{tabular}

immediately adjacent to the acceptor, as shown in Fig. 2(a). The $\mathrm{O}-\mathrm{H}$ bond points toward the largest interstitial site, similar to the isolated $\mathrm{H}_{\mathrm{i}}^{+}$. The stability of the complexes was assessed by calculating $\mathrm{H}$ removal energies, which is defined as the difference in formation energy between the charge-neutral complex and the sum of the two isolated constituents (negatively charged acceptor and $\left.\mathrm{H}_{\mathrm{i}}^{+}\right){ }^{19}$ The resulting removal energies of $0.68,0.84,0.78$, 0.79 , and $1.01 \mathrm{eV}$ for $\mathrm{Mg}_{\mathrm{Ga} 2} \mathrm{H}, \mathrm{Ca}_{\mathrm{Ga} 2} \mathrm{H}, \mathrm{Cd}_{\mathrm{Ga} 2} \mathrm{H}, \mathrm{Zn}_{\mathrm{Ga} 1} \mathrm{H}$, and $\mathrm{Be}_{\mathrm{Ga}} \mathrm{H}$, respectively, are relatively low considering the modest migration barrier predicted for $\mathrm{H}_{\mathrm{i}}^{+}{ }^{26}$ Initially, these complexes should be stable at room temperature; however, dissociation might occur upon UV light exposure, which would lead to bleaching of their PL bands. Indeed, recombination-enhanced dissociation has been observed, e.g., for the $\mathrm{C}_{\mathrm{N}} \mathrm{H}$ complex in $\mathrm{GaN}{ }^{50}$ As shown in Fig. 2, optical transitions between the CBM and the
$(+/ 0)$ level of the $\mathrm{H}$-complexed acceptors results in PL bands peaking between 2.57 and $2.76 \mathrm{eV}$. Thus, complexing the polaronic acceptors with $\mathrm{H}$ will not passivate the luminescence, but rather shift it to higher energies.

Based on our theoretical predictions, isolated and $\mathrm{H}$-complexed polaronic acceptor impurities are potential candidates for luminescence bands observed in the visible part of the spectrum. Indeed, increases in the intensity of BL and GL bands have been reported in experimental cathodoluminescence studies on $\mathrm{Mg}$ - and $\mathrm{Zn}$-doped $\beta$ - $\mathrm{Ga}_{2} \mathrm{O}_{3} \cdot{ }^{10,15} \mathrm{We}$ also note that the calculated absorption energies of the polaronic acceptor impurities are very close to the bandgap energy, which means that their luminescence bands could be selectively excited with photon energies slightly below the bandgap. This was observed experimentally for the BL band in Refs. 5 and 7. 
a)
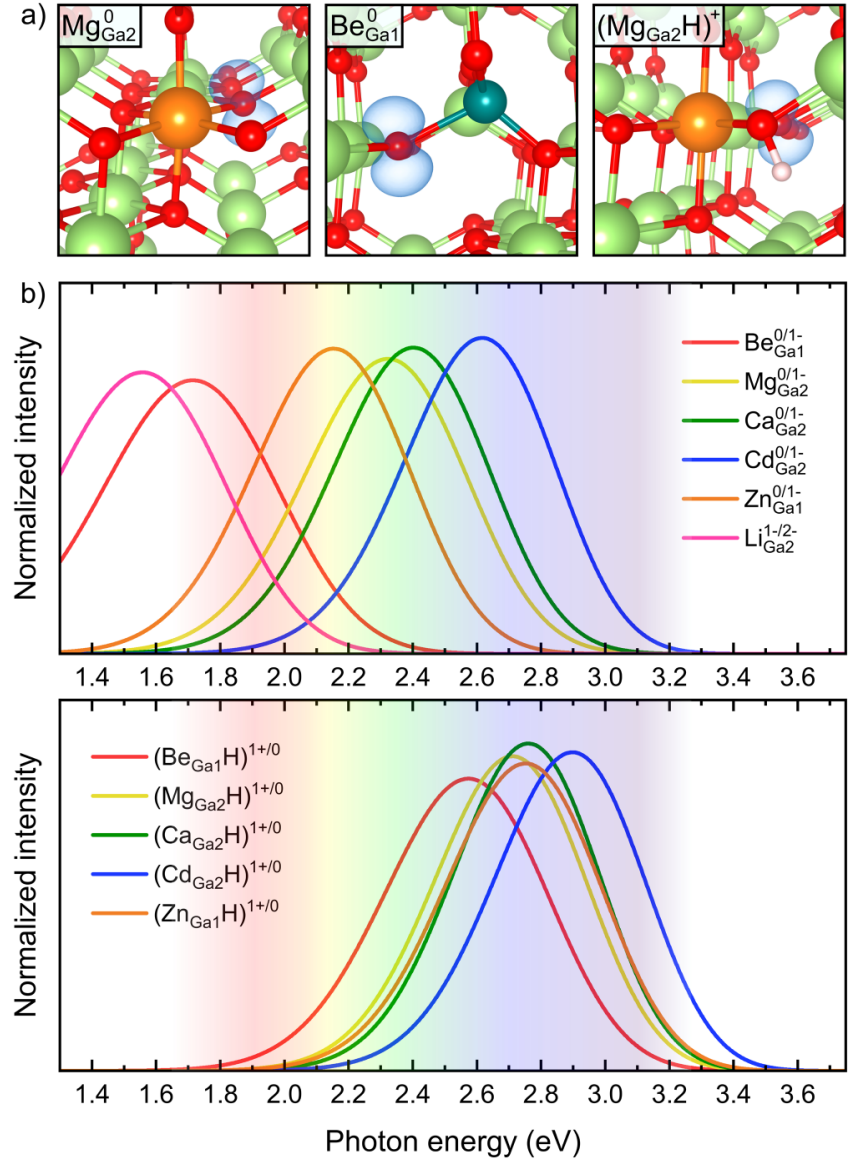

FIG. 2. (a) Ground-state configuration of $\mathrm{Mg}_{\mathrm{Ga} 2}^{0}, \mathrm{Be}_{\mathrm{Ga} 1}^{0}$, and $\left(\mathrm{Mg}_{\mathrm{Ga} 2} \mathrm{H}\right)^{+}$. The hole polaron most favorably localizes on a single nearest-neighbor $\mathrm{O} 1$ site in all cases. (b) Calculated luminescence lines for optical transitions involving isolated (top) and $\mathrm{H}$-decorated (bottom) polaronic acceptors.

\section{Ga vacancies}

$V_{\mathrm{Ga}}$ acts as a polaronic triple acceptor in $\beta-\mathrm{Ga}_{2} \mathrm{O}_{3}$ and could be involved in donor-acceptor pair transitions, similar to the impurities above. ${ }^{5}$ Moreover, the formation energy of $V_{\mathrm{Ga}}$ is sufficiently low for it to be incorporated in sizeable concentrations during growth, particularly under O-rich and $n$-type conditions. ${ }^{27,51}$ In addition to the $V_{\mathrm{Ga} 1}$ and $V_{\mathrm{Ga} 2}$ configurations, there are three splitvacancy configurations where two adjacent vacant $\mathrm{Ga}$ sites are complexed with a Ga residing between them in a high-symmetry interstitial site; these are denoted as $V_{\mathrm{Ga}}^{\mathrm{ia}}, V_{\mathrm{Ga}}^{\mathrm{ib}}$, and $V_{\mathrm{Ga}}^{\mathrm{ic}}{ }^{51}$ The thermodynamic $(2-/ 3-)$ transition levels of the five different $V_{\mathrm{Ga}}$ configurations have been predicted to occur between 1.7 and $2.6 \mathrm{eV}$ below the CBM. ${ }^{51}$ We find that optical transitions between the $\mathrm{CBM}$ and these $(2-/ 3-)$ levels result in emission energies between 0.1 and $1.2 \mathrm{eV}$, which is much lower than the characteristic luminescence bands observed in $\beta-\mathrm{Ga}_{2} \mathrm{O}_{3}$. Moreover, these transitions are likely to have significant nonradiative components
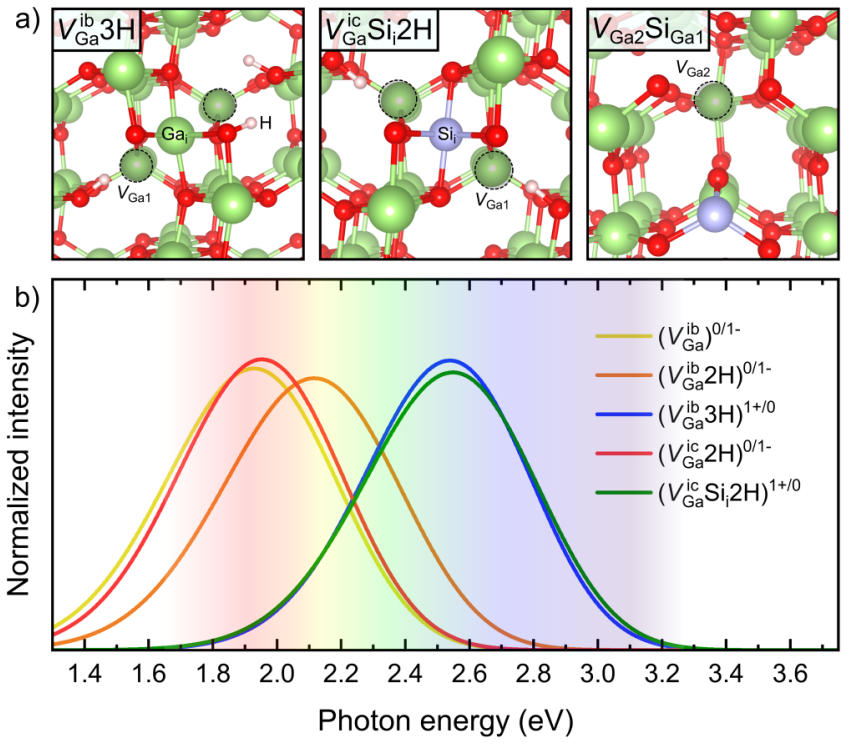

FIG. 3. (a) Relaxed structures of the $V_{G a}^{i b} 3 H$, $V_{G a}^{i c} S i_{i} 2 H$, and $V_{G a 2} S i_{G a 1}$ complexes. The $\mathrm{Ga}$ vacancies are indicated with dashed translucent circles. (b) Calculated luminescence lines of four $V_{G a}$ acceptors complexed with $H$ and $\mathrm{Si}_{\mathrm{Ga}}$ donors.

due to crossing between the ground- and excited-state potential energy curves in their CC diagrams. ${ }^{52}$ In principle, $V_{\mathrm{Ga}}$ in the $3-$ charge state can radiatively capture photogenerated holes from the VBM. However, if the lack of NBE is caused by formation of STHs, such transitions are not likely be observed. Moreover, since both the VB of $\beta-\mathrm{Ga}_{2} \mathrm{O}_{3}$ and the polaronic defect states exhibit mostly $2 p$ character, the transition dipole moment should be weak. Nevertheless, we obtain emission energies between 1.3 and $2.3 \mathrm{eV}$ for these optical transitions of the five different $V_{\mathrm{Ga}}$ acceptors.

However, $V_{\mathrm{Ga}}$ can form stable complexes with shallow donor impurities such as $\mathrm{H}$ and $\mathrm{Si}_{\mathrm{Ga}}{ }^{27,53}$ Notably, the $V_{\mathrm{Ga}}^{\mathrm{ib}} 2 \mathrm{H}$ complex has been assigned to an IR absorption line $3436 \mathrm{~cm}^{-1}$ by Weiser et al. ${ }^{54}$ Complexing $V_{\mathrm{Ga}}$ with shallow single donors will successively passivate its acceptor levels, thereby shifting its luminescence to higher energies, similar to the $\mathrm{H}$-complexed polaronic acceptor impurities in Fig. 2. There is a large number of possible donorcomplexed $V_{\mathrm{Ga}}$ acceptors to explore. As examples, we have included results for $V_{\mathrm{Ga} 2} \mathrm{Si}_{\mathrm{Ga} 1}, V_{\mathrm{Ga}}^{\mathrm{ib}} 2 \mathrm{H}, V_{\mathrm{Ga}}^{\mathrm{ib}} 3 \mathrm{H}, V_{\mathrm{Ga}}^{\mathrm{ic}} 2 \mathrm{H}$, and $V_{\mathrm{Ga}}^{\mathrm{ic}} \mathrm{Si}_{\mathrm{i}} 2 \mathrm{H}$ in Table I. As shown in Fig. 3(a), the $\mathrm{H}$ atoms terminate $\mathrm{O}$ dangling bonds at $V_{\mathrm{Ga}}$ in all cases, while the $\mathrm{Si}$ atom goes off-site in the $V_{\mathrm{Ga}}^{\mathrm{ic}} \mathrm{Si}_{\mathrm{i}} 2 \mathrm{H}$ complex and occupies a Gal site immediately adjacent to $V_{\mathrm{Ga} 2}$ in the $V_{\mathrm{Ga} 2} \mathrm{Si}_{\mathrm{Ga} 1}$ complex. Figure 3 (b) shows that the complexes with two and three donor impurities can give rise to luminescence lines with predicted peak positions in the visible range. Hence, such complexes are also potential candidates for the characteristic visible luminescence bands observed in $\beta$ - $\mathrm{Ga}_{2} \mathrm{O}_{3}$. It should be noted that, in high-resistive material, the isolated $V_{\mathrm{Ga}}$ acceptors could occur in $2-$ or $1-$ charge states. ${ }^{51,55}$ 
Under such conditions, optical transitions between the CBM and the $(-/ 2-)$ or $(0 /-)$ levels of $V_{\mathrm{Ga}}$ might result in luminescence bands peaking in the visible range, similar to the donorcomplexed $V_{\mathrm{Ga}}$ acceptors above.

\section{Nitrogen acceptor impurities}

Turning to $\mathrm{N}$ impurities substituting on $\mathrm{O}$ sites, the most favorable configuration depends on the Fermi level position. ${ }^{23}$ In typical unintentionally $n$-type doped material, $\mathrm{N}_{\mathrm{O}}$ will act as a compensating acceptor. Under such conditions, the $\mathrm{N}_{\mathrm{O} 3}$

a)
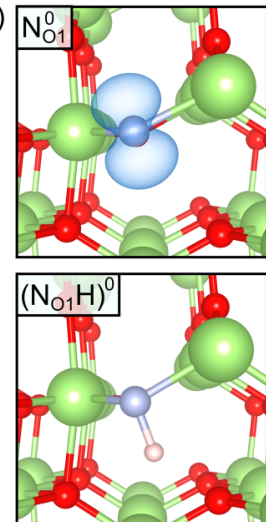

b)
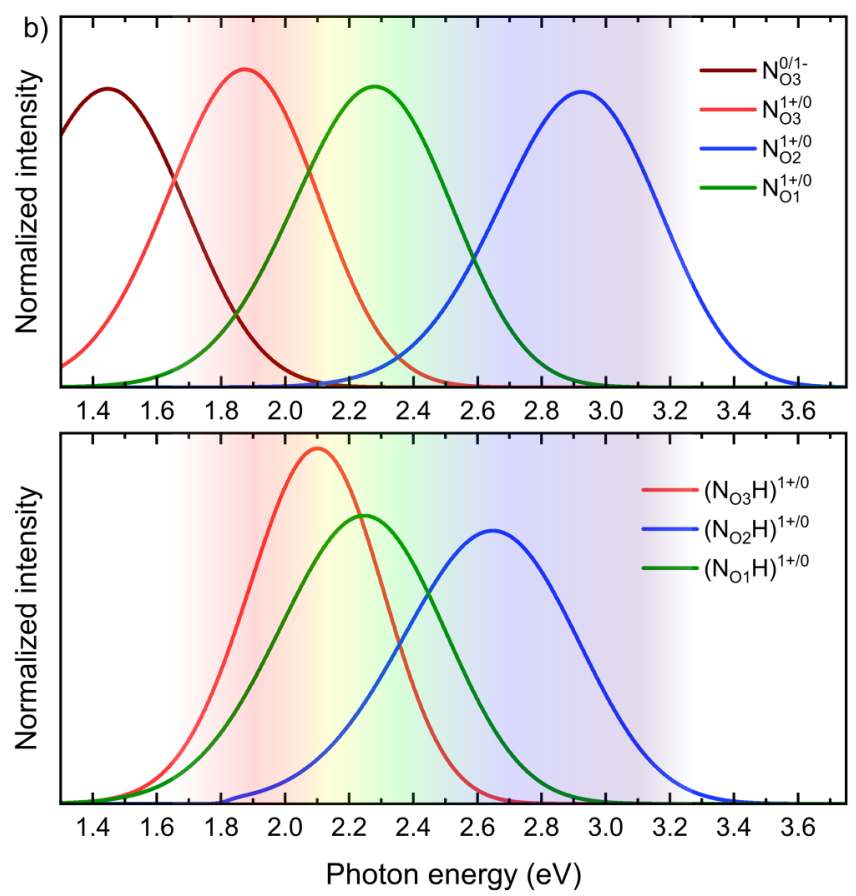

FIG. 4. (a) Relaxed structures of $\mathrm{N}_{01}^{0}, \mathrm{~N}_{\mathrm{O} 2}^{0}, \mathrm{~N}_{\mathrm{O} 3}^{0},\left(\mathrm{~N}_{\mathrm{O} 1} \mathrm{H}\right)^{0},\left(\mathrm{~N}_{\mathrm{O} 2} \mathrm{H}\right)^{0}$, and $\left(\mathrm{N}_{03} \mathrm{H}\right)^{0}$. For $\mathrm{N}_{\mathrm{O}}$ acceptors, the hole state (blue isosurface) is localized at the $\mathrm{N}$ impurity itself, rather than an adjacent $\mathrm{O}$ site. (b) Calculated luminescence lines for optical transitions involving $\mathrm{N}_{\mathrm{O}}$ and $\mathrm{N}_{0} \mathrm{H}$ complexes. configuration exhibits the lowest formation energy. However, a high concentration of $\mathrm{N}_{\mathrm{O}}$ will drive the Fermi level toward the $(0 /-)$ transition level, where the charge-neutral $\mathrm{N}_{\mathrm{O} 1}$ and $\mathrm{N}_{\mathrm{O} 2}$ may become relevant. ${ }^{23}$ All three $\mathrm{N}_{\mathrm{O}}$ configurations also exhibit a thermodynamic $(+/ 0)$ transition level located in the lower part of the bandgap. For the $\mathrm{N}_{\mathrm{O}}$ acceptors, the neutral and positive charge states correspond to hole states that are localized at the $\mathrm{N}$ impurity itself, rather than a neighboring $\mathrm{O}$ site, as shown in Fig. 4(a).

We have focused on optical transitions between the CBM and the thermodynamic $(+/ 0)$ charge-state transition level of $\mathrm{N}_{\mathrm{O} 1}$ and $\mathrm{N}_{\mathrm{O} 2}$, and both the $(+/ 0)$ and $(0 /-)$ levels for $\mathrm{N}_{\mathrm{O} 3}$. As shown in Fig. 4(b), the luminescence lines involving $\mathrm{N}_{\mathrm{O}}$ depend strongly on the configuration, and thus the Fermi level position. In $n$-type material, electron capture from the CBM by charge-neutral $\mathrm{N}_{\mathrm{O} 3}$ results in a broad luminescence band peaking at $1.44 \mathrm{eV}$. For highresistive material, where $\mathrm{N}_{\mathrm{O}}$ preferably adopts the neutral charge-state, optical transitions between the CBM and the $(+/ 0)$ level of $\mathrm{N}_{\mathrm{O} 3}, \mathrm{~N}_{\mathrm{O} 2}$, and $\mathrm{N}_{\mathrm{O} 1}$ result in bands peaking at 1.87, 2.94, and $2.28 \mathrm{eV}$, respectively.

As shown in Fig. 4(a), hydrogen can passivate the $(0 /-)$ acceptor levels of $\mathrm{N}_{\mathrm{O}}$ by forming a bond with the $\mathrm{N}$ impurity. The resulting $\mathrm{N}_{\mathrm{O} 1} \mathrm{H}, \mathrm{N}_{\mathrm{O} 2} \mathrm{H}$, and $\mathrm{N}_{\mathrm{O} 3} \mathrm{H}$ complexes exhibit $\mathrm{H}$ removal energies of $2.18,1.95$, and $0.27 \mathrm{eV}$, respectively. The latter removal energy is so low that the $\mathrm{N}_{\mathrm{O}} \mathrm{H}$ complex could be unstable at room temperature. Most likely, this is because $\mathrm{N}_{\mathrm{O} 3}$ is fourfold- and not threefold-coordinated like $\mathrm{N}_{\mathrm{O} 1}$ and $\mathrm{N}_{\mathrm{O} 2}$ [see Fig. 4(a)]. In contrast, the $\mathrm{N}_{\mathrm{O} 1} \mathrm{H}$ and $\mathrm{N}_{\mathrm{O} 2} \mathrm{H}$ complexes are predicted to be highly stable. The $\mathrm{N}_{\mathrm{O} 1} \mathrm{H}$ complex exhibits the lowest formation energy, but it is only $0.13 \mathrm{eV}$ lower than that for $\mathrm{N}_{\mathrm{O} 2} \mathrm{H}$. Optical transitions between the $\mathrm{CBM}$ and the $(+/ 0)$ transition levels of the $\mathrm{N}_{\mathrm{O} 1} \mathrm{H}, \mathrm{N}_{\mathrm{O} 2} \mathrm{H}$, and $\mathrm{N}_{\mathrm{O} 3} \mathrm{H}$ complexes result in broad luminescence bands with calculated PPs of $2.25,2.65$, and $2.10 \mathrm{eV}$, respectively.

As already mentioned, the emission from $\mathrm{N}_{\mathrm{O}}$-related defects will depend strongly on the configuration, which is important to consider when comparing the predictions with experimental data. Song et al. ${ }^{56}$ observed an intense red luminescence (RL) band peaking at $1.67 \mathrm{eV}$ in $\mathrm{N}$-doped $\beta-\mathrm{Ga}_{2} \mathrm{O}_{3}$ nanowires. This is close to the luminescence bands calculated for $\mathrm{N}_{\mathrm{O} 3}$. RL has also been observed in $\mathrm{N}$-doped $\beta-\mathrm{Ga}_{2} \mathrm{O}_{3}$ nanoflakes. ${ }^{57}$ In contrast, Harwig and Kellendonk ${ }^{5}$ observed no RL, but a slight increase in the $\mathrm{BL}$ band intensity when $\beta-\mathrm{Ga}_{2} \mathrm{O}_{3}$ powders were fired in $\mathrm{N}_{2}$ vs air. In a cathodoluminescence study by Onuma et al., ${ }^{11}$ however, the $\mathrm{BL}$ band was suppressed in heavily $\mathrm{N}$-doped epitaxial $\beta-\mathrm{Ga}_{2} \mathrm{O}_{3}$ films.

\section{CONCLUSION}

By using 1D CC diagrams derived from hybrid functional calculations, we have estimated optical transition energies and luminescence lines for acceptor impurities $\mathrm{Mg}_{\mathrm{Ga} 2}, \mathrm{Be}_{\mathrm{Ga}}, \mathrm{Ca}_{\mathrm{Ga} 2}$, $\mathrm{Cd}_{\mathrm{Ga} 2}, \mathrm{Zn}_{\mathrm{Ga} 1}, \mathrm{Li}_{\mathrm{Ga} 2}$, and $\mathrm{N}_{\mathrm{O}}$, their complexes with $\mathrm{H}$ donors, as well as $V_{\mathrm{Ga}}$ acceptors complexed with hydrogen and $\mathrm{Si}_{\mathrm{Ga}}$ donor impurities in $\beta-\mathrm{Ga}_{2} \mathrm{O}_{3}$. The results point to these acceptors as possible candidates for the origin of broad PL bands in the infrared to visible part of the emission spectrum. Specifically, the calculated luminescence lines of $\mathrm{Mg}_{\mathrm{Ga} 2}, \mathrm{Ca}_{\mathrm{Ga} 2}, \mathrm{Cd}_{\mathrm{Ga} 2}$, and $\mathrm{Zn}_{\mathrm{Ga} 1}$ peak in the 2.15-2.62 eV range (green/blue), while those of $\mathrm{Be}_{\mathrm{Ga}}$ 
and $\mathrm{Li}_{\mathrm{Ga} 2}$ peak at lower energies of 1.71 and $1.56 \mathrm{eV}$ (infrared/ red), respectively. $V_{\mathrm{Ga}}$ acceptors complexed with shallow donor impurities such as $\mathrm{H}$ and $\mathrm{Si}_{\mathrm{Ga}}$ can similarly give rise to luminescence in the visible range. For $\mathrm{N}_{\mathrm{O}}$ acceptors, the luminescence depends strongly on the configuration and Fermi level position. The $\mathrm{N}_{\mathrm{O} 3}$ configuration, which has the lowest formation energy in $n$-type material, can give rise to luminescence bands with predicted peak positions at 1.44 and $1.87 \mathrm{eV}$ (infrared/red), whereas the luminescence lines of $\mathrm{N}_{\mathrm{O} 1}$ and $\mathrm{N}_{\mathrm{O} 2}$ peak at higher energies of 2.28 and $2.92 \mathrm{eV}$ (green and blue), respectively. When the acceptor impurities are complexed with a single $\mathrm{H}$ donor, we find that the luminescence band is not passivated, but rather shifted in peak position. These results could be useful for future optical studies seeking to identify the origin of the broad luminescence bands in $\beta-\mathrm{Ga}_{2} \mathrm{O}_{3}$.

\section{ACKNOWLEDGMENTS}

We wish to thank A. Alkauskas for fruitful collaborations and for providing the code and expertise to calculate luminescence lineshapes, and T. Gake, Y. Kumagai, and F. Oba for helpful discussions. Financial support was kindly provided by the Research Council of Norway and University of Oslo through the frontier research project FUNDAMeNT (No. 251131, FriPro ToppForsk-program). The computations were performed on resources provided by UNINETT Sigma2-the National Infrastructure for High Performance Computing and Data Storage in Norway. This work was partially performed under the auspices of the U.S. Department of Energy (DOE), Lawrence Livermore National Laboratory under Contract No. DE-AC52-07NA27344 and supported by the Critical Materials Institute, an Energy Innovation Hub funded by the U.S. DOE, Office of Energy Efficiency and Renewable Energy, Advanced Manufacturing Office.

\section{APPENDIX: PBEO calculations and test of finite-size corrections}

In order to (i) assess how sensitive our theoretical predictions are to the parameterization of the hybrid functional, i.e., choice of $\alpha$ and $\mu$ parameters, and (ii) elaborate on possible non-Koopmans behavior, we have performed calculations using the PBE0 functional, which yields the same direct bandgap value of $4.9 \mathrm{eV}$. Calculations were performed for a representative subset of the defects studied in the present work, namely, the STHs, two polaronic acceptors $\left(\mathrm{Mg}_{\mathrm{Ga} 2}\right.$ and $\left.\mathrm{Mg}_{\mathrm{Ga} 2} \mathrm{H}\right)$ and one $\mathrm{O}$ substitutional $\mathrm{N}$

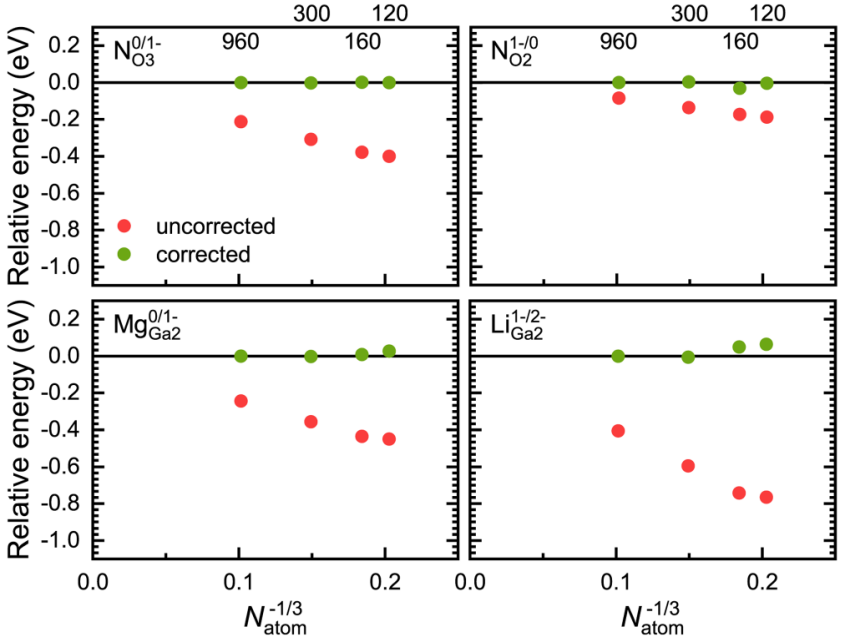

FIG. 5. Dependence of the corrected and uncorrected vertical transition energies of defects on the supercell size. Calculations were performed using the $\mathrm{PBE}+\mathrm{U}$ functional. The vertical transition energies are given relative to the corrected one in the largest 960 atom supercell.

acceptor $\left(\mathrm{N}_{\mathrm{O} 3}\right)$. The results are listed in Table II. The calculated PPs shift up in energy when the PBE0 functional is used, but the magnitude is only $0.1 \mathrm{eV}$ at most. Based on this, we conclude that the qualitative results do not hinge on the specific HSE parameterization. Regarding the generalized Koopmans condition, our results are similar to those reported by Gake et al., ${ }^{39}$ i.e., we find that the acceptor impurities exhibit slightly convex behavior when using the HSE functional. If the parameterization is tuned to satisfy the generalized Koopmans condition, the resulting bandgap is overestimated. ${ }^{39}$ When PBE0 is used, the convexity is only slightly reduced, e.g., for the (0/-) transition of $\mathrm{Mg}_{\mathrm{Ga} 2}$ we obtain a non-Koopmans energy (see Ref. 34) of $0.24 \mathrm{eV}$ for HSE and $0.20 \mathrm{eV}$ for PBE0.

Gake et al $^{43}$ recently proposed a scheme to remedy the spurious supercell-size dependence of vertical transition energies involving defect states. These corrections translate into different effective Franck-Condon relaxation energies that can differ from those evaluated using either no finite-size corrections or those corrected with only the low-frequency dielectric screening. ${ }^{58}$ As shown in Fig. 5, we have evaluated the performance of this finite-size correction by performing supercell-size tests

TABLE II. PP and FWHM for the calculated luminescence lines, and CC model parameters obtained from the PBE0 calculations. The change in PP compared to the value calculated using HSE is given in parenthesis.

\begin{tabular}{lccccccc}
\hline \hline Optical transition & $\mathrm{PP}(\mathrm{eV})$ & FWHM $(\mathrm{eV})$ & $E_{\mathrm{ZPL}}(\mathrm{eV})$ & $E_{\mathrm{em}}(\mathrm{eV})$ & $E_{\mathrm{abs}}(\mathrm{eV})$ & $\Delta Q\left(\mathrm{amu}{ }^{1 / 2} / \AA\right)$ & $\hbar \Omega_{\mathrm{g} / \mathrm{e}}(\mathrm{meV})$ \\
\hline $\mathrm{STH}_{\mathrm{O} 1}^{+}+e_{\mathrm{CBM}}^{-}$ & $3.18(+0.07)$ & 0.54 & 4.38 & 3.13 & 5.35 & 2.69 & $38 / 34$ \\
$\mathrm{STH}_{\mathrm{O} 2}^{+}+e_{\mathrm{CBM}}^{-}$ & $3.07(+0.03)$ & 0.59 & 4.28 & 2.98 & 5.30 & 2.26 & $46 / 41$ \\
$\mathrm{Mg}_{\mathrm{Ga} 2}^{+}+e_{\mathrm{CBM}}^{-}$ & $2.42(+0.10)$ & 0.56 & 3.72 & 2.30 & 4.67 & 2.63 & $41 / 34$ \\
$\left(\mathrm{Mg}_{\mathrm{Ga} 2} \mathrm{H}\right)^{+}+e_{\mathrm{CBM}}^{-}$ & $2.80(+0.09)$ & 0.60 & 4.02 & 2.70 & 5.00 & 2.65 & $40 / 34$ \\
$\mathrm{~N}_{\mathrm{O} 3}^{0}+e_{\mathrm{CBM}}^{-}$ & $1.54(+0.10)$ & 0.58 & 2.88 & 1.38 & 3.95 & 2.75 & $41 / 34$ \\
\hline \hline
\end{tabular}


of the vertical transitions for a representative set of the defects studied in the present work. We employed the $\mathrm{PBE}+\mathrm{U}$ functional with an effective $U$ value of $10 \mathrm{eV}$ applied to the $\mathrm{O} 2 p$ orbitals in order to increase the bandgap and ensure well localized defect states, similar in character to those obtained using the hybrid functional, in both the initial and final charge state. Furthermore, the use of the $\mathrm{PBE}+\mathrm{U}$ functional makes it computationally feasible to employ large supercells. Specifically, we have used supercells with 120,160, 300, and 960 atoms. Note that, since the cell dimension is not isotropically expanded, we have not performed any extrapolation of the uncorrected energies to the dilute limit. We have used the point charge correction with the alignment term, as explained in Ref. 43. Figure 5 shows that the vertical transition energies are well corrected. The difference between the corrected energy in the 160 and 960 atom supercell is less than $0.03 \mathrm{eV}$ for the transitions involving charge-neutral and singly charged defects, and $0.05 \mathrm{eV}$ for the $\mu(-/ 2-)$ transition of $\mathrm{Li}_{\mathrm{Ga} 2}$. We have also confirmed that the formation energies of the defects shown in the supercell-size tests were well corrected.

\section{REFERENCES}

${ }^{1}$ S. Pearton, J. Yang, P. Cary, F. Ren, J. Kim, M. Tadjer, and M. Mastro, Appl. Phys. Rev. 5, 011301 (2018).

${ }^{2}$ M. E. Ingebrigtsen, J. B. Varley, A. Y. Kuznetsov, B. G. Svensson, G. Alfieri, A. Mihaila, U. Badstöbner, and L. Vines, Appl. Phys. Lett. 112, 042104 (2018).

${ }^{3}$ J. F. McGlone, Z. Xia, C. Joishi, S. Lodha, S. Rajan, S. Ringel, and A. R. Arehart, Appl. Phys. Lett. 115, 153501 (2019).

${ }^{4}$ T. Harwig, F. Kellendonk, and S. Slappendel, J. Phys. Chem. Solids 39, 675 (1978).

${ }^{\mathbf{5}}$ T. Harwig and F. Kellendonk, J. Phys. Chem. Solids 24, 255 (1978).

${ }^{6}$ G. Blasse and A. Bril, J. Chem. Phys. Solids 31, 707 (1970).

${ }^{7}$ L. Binet and D. Gourier, J. Chem. Phys. Solids 59, 1241 (1998).

${ }^{8}$ K. Shimamura, E. G. Víllora, T. Ujiie, and K. Aoki, Appl. Phys. Lett. 92, 201914 (2008).

${ }^{9}$ M. Yamaga, T. Ishikawa, M. Yoshida, T. Hasegawa, E. G. Villora, and K. Shimamura, Phys. Status Solidi C 8, 2621 (2011).

${ }^{10}$ T. Onuma, S. Fujioka, T. Yamaguchi, M. Higashiwaki, K. Sasaki, T. Masui, and T. Honda, Appl. Phys. Lett. 103, 041910 (2013).

${ }^{11}$ T. Onuma, Y. Nakata, K. Sasaki, T. Masui, T. Yamaguchi, T. Honda, A. Kuramata, S. Yamakoshi, and M. Higashiwaki, J. Appl. Phys. 124, 075103 (2018).

${ }^{12}$ Y. Wang, P. T. Dickens, J. B. Varley, X. Ni, E. Lotubai, S. Sprawls, F. Liu, V. Lordi, S. Krishnamoorthy, S. Blair, K. G. Lynn, M. Scarpulla, and B. Sensale-Rodriguez, Sci. Rep. 8, 18075 (2018).

${ }^{13}$ J. B. Varley, A. Janotti, C. Franchini, and C. G. Van de Walle, Phys. Rev. B 85, 081109 (2012).

${ }^{14}$ B. E. Kananen, N. C. Giles, L. E. Halliburton, G. K. Foundos, K. B. Chang, and K. T. Stevens, J. Appl. Phys. 122, 215703 (2017).

${ }^{15}$ X. Wang, F. Zhang, K. Saito, T. Tanaka, M. Nishio, and Q. Guo, J. Phys. Chem. Solids 75, 1201 (2014).

${ }^{16}$ Q. D. Ho, T. Frauenheim, and P. Deák, Phys. Rev. B 97, 115163 (2018).

${ }^{17}$ H. Gao, S. Muralidharan, N. Pronin, M. R. Karim, S. M. White, T. Asel, G. Foster, S. Krishnamoorthy, S. Rajan, L. R. Cao, M. Higashiwaki, H. von Wenckstern, M. Grundmann, H. Zhao, D. C. Look, and L. J. Brillson, Appl. Phys. Lett. 112, 242102 (2018).

${ }^{18}$ A. Alkauskas, J. L. Lyons, D. Steiauf, and C. G. Van de Walle, Phys. Rev. Lett. 109, 267401 (2012).
${ }^{19}$ C. Freysoldt, B. Grabowski, T. Hickel, J. Neugebauer, G. Kresse, A. Janotti, and C. G. Van de Walle, Rev. Mod. Phys. 86, 253 (2014).

${ }^{20}$ A. Alkauskas, M. D. McCluskey, and C. G. Van de Walle, J. Appl. Phys. 119, 181101 (2016).

${ }^{21}$ M. Higashiwaki, K. Sasaki, H. Murakami, Y. Kumagai, A. Koukitu, A. Kuramata, T. Masui, and S. Yamakoshi, Semicond. Sci. Technol. 31, 034001 (2016).

${ }^{22}$ J. L. Lyons, Semicond. Sci. Technol. 33, 05LT02 (2018).

${ }^{23}$ H. Peelaers, J. L. Lyons, J. B. Varley, and C. G. Van de Walle, APL Mater. 7, 022519 (2019).

${ }^{\mathbf{2 4}}$ C. Lin, Y. Yuda, M. H. Wong, M. Sato, N. Takekawa, K. Konishi, T. Watahiki, M. Yamamuka, H. Murakami, Y. Kumagai, and M. Higashiwaki, IEEE Electron Device Lett. 40, 1487 (2019).

${ }^{25}$ Z. Galazka, K. Irmscher, R. Schewski, I. M. Hanke, M. Pietsch, S. Ganschow, D. Klimm, A. Dittmar, A. Fiedler, T. Schroeder, and M. Bickermann, J. Cryst. Growth 529, 125297 (2020).

${ }^{\mathbf{2 6}}$ J. B. Varley, J. R. Weber, A. Janotti, and C. G. Van de Walle, Appl. Phys. Lett. 97, $142106(2010)$.

27J. B. Varley, H. Peelaers, A. Janotti, and C. G. V. de Walle, J. Phys. Condens. Matter 23, 334212 (2011).

${ }^{28}$ J. R. Ritter, J. Huso, P. T. Dickens, J. B. Varley, K. G. Lynn, and M. D. McCluskey, Appl. Phys. Lett. 113, 052101 (2018).

${ }^{29}$ P. E. Blöchl, Phys. Rev. B 50, 17953 (1994).

${ }^{30}$ G. Kresse and D. Joubert, Phys. Rev. B 59, 1758 (1999).

${ }^{31}$ G. Kresse and J. Furthmüller, Phys. Rev. B 54, 11169 (1996).

${ }^{32}$ A. V. Krukau, O. A. Vydrov, A. F. Izmaylov, and G. E. Scuseria, J. Chem. Phys. 125, 224106 (2006).

${ }^{33}$ H. Peelaers and C. G. Van de Walle, Phys. Status Solidi B 252, 828 (2015).

${ }^{34}$ S. Lany and A. Zunger, Phys. Rev. B 80, 085202 (2009).

${ }^{35}$ V. Ivády, I. A. Abrikosov, E. Janzén, and A. Gali, Phys. Rev. B 87, 205201 (2013).

36. Badigh, P. Erhart, and D. Åberg, Phys. Rev. B 92, 075202 (2015).

${ }^{37}$ P. Deák, Q. Duy Ho, F. Seemann, B. Aradi, M. Lorke, and T. Frauenheim, Phys. Rev. B 95, 075208 (2017).

${ }^{38}$ D. O. Demchenko, I. C. Diallo, and M. A. Reshchikov, Phys. Rev. B 97, 205205 (2018).

${ }^{39}$ T. Gake, Y. Kumagai, and F. Oba, Phys. Rev. Mater. 3, 044603 (2019).

${ }^{40}$ Y. Kumagai and F. Oba, Phys. Rev. B 89, 195205 (2014).

${ }^{41}$ C. Freysoldt, J. Neugebauer, and C. G. Van de Walle, Phys. Rev. Lett. 102, 016402 (2009).

${ }^{42}$ M. Schubert, R. Korlacki, S. Knight, T. Hofmann, S. Schöche, V. Darakchieva, E. Janzén, B. Monemar, D. Gogova, Q.-T. Thieu, R. Togashi, H. Murakami, Y. Kumagai, K. Goto, A. Kuramata, S. Yamakoshi, and M. Higashiwaki, Phys. Rev. B 93, 125209 (2016).

${ }^{43}$ T. Gake, Y. Kumagai, C. Freysoldt, and F. Oba, "Finite-size corrections for defect-involving vertical transitions in supercell calculations," Phys. Rev. B 101, 020102 (2020).

${ }^{44}$ C. Janowitz, V. Scherer, M. Mohamed, A. Krapf, H. Dwelk, R. Manzke, Z. Galazka, R. Uecker, K. Irmscher, R. Fornari, M. Michling, D. Schmeißer, J. R. Weber, J. B. Varley, and C. G. V. de Walle, New J. Phys. 13, 085014 (2011).

${ }^{45}$ Y. K. Frodason, K. M. Johansen, T. S. Bjørheim, B. G. Svensson, and A. Alkauskas, Phys. Rev. B 95, 094105 (2017).

${ }^{46}$ Y. K. Frodason, K. M. Johansen, T. S. Bjorheim, B. G. Svensson, and A. Alkauskas, Phys. Rev. B 97, 104109 (2018).

${ }^{47}$ B. E. Kananen, L. E. Halliburton, E. M. Scherrer, K. T. Stevens, G. K. Foundos, K. B. Chang, and N. C. Giles, Appl. Phys. Lett. 111, 072102 (2017).

${ }^{48}$ Y. K. Frodason, K. M. Johansen, A. Galeckas, and L. Vines, Phys. Rev. B 100, 184102 (2019).

49. L. Lyons, A. Janotti, and C. G. Van de Walle, J. Appl. Phys. 115, 012014 (2014).

${ }^{50}$ D. O. Demchenko, I. C. Diallo, and M. A. Reshchikov, J. Appl. Phys. 119, 035702 (2016). 
${ }^{51}$ M. E. Ingebrigtsen, A. Y. Kuznetsov, B. G. Svensson, G. Alfieri, A. Mihaila, U. Badstübner, A. Perron, L. Vines, and J. B. Varley, APL Mater. 7, 022510 (2019).

${ }^{52}$ A. Alkauskas, Q. Yan, and C. G. Van de Walle, Phys. Rev. B 90, 075202 (2014).

${ }^{53}$ S. Lany, APL Mater. 6, 046103 (2018).

${ }^{54}$ P. Weiser, M. Stavola, W. B. Fowler, Y. Qin, and S. Pearton, Appl. Phys. Lett. 112, 232104 (2018).
${ }^{55}$ B. E. Kananen, L. E. Halliburton, K. T. Stevens, G. K. Foundos, and N. C. Giles, Appl. Phys. Lett. 110, 202104 (2017).

${ }^{56}$ Y. P. Song, H. Z. Zhang, C. Lin, Y. W. Zhu, G. H. Li, F. H. Yang, and D. P. Yu, Phys. Rev. B 69, 075304 (2004).

${ }^{57}$ G. Pozina, M. Forsberg, M. A. Kaliteevski, and C. Hemmingsson, Sci. Rep. 7, 42132 (2017).

${ }^{58}$ E. Farzana, A. Mauze, J. B. Varley, T. E. Blue, J. S. Speck, A. R. Arehart, and S. A. Ringel, APL Mater. 7, 121102 (2019). 